\title{
Cleaning of Ceramic Ultrafiltration Membranes After Filtration of Hay Hydrolysate
}

\author{
Kamila Gruskevica \\ Water Research and Environmental \\ Biotechnology Laboratory \\ Riga Technical University \\ Riga, Latvia \\ kamila.gruskevica@rtu.lv \\ Linda Mezule \\ Water Research and Environmental \\ Biotechnology Laboratory \\ Riga Technical University \\ Riga, Latvia \\ linda.mezule@rtu.lv
}

\author{
Matrins Strods \\ Water Research and Environmental \\ Biotechnology Laboratory \\ Riga Technical University \\ Riga, Latvia \\ martins.strods_4@rtu.lv
}

\author{
Janis Rubulis \\ Water Research and Environmental \\ Biotechnology Laboratory \\ Riga Technical University \\ Riga, Latvia \\ janis.rubulis@rtu.lv
}

\begin{abstract}
Hydrolysis of the lignocellulosic biomass results in the release of high-value chemicals that during industrial processing can be recovered with membrane technologies. To maintain an effective performance of the membranes used in the technological processing of biomass, their regular cleaning is essential. Although several guidelines may be found for membrane cleaning in the cases of organic fouling, the data for cleaning membranes fouled by hydrolyzed lignocellulosic biomass is limited. Current research is aimed to evaluate physical (air backpulse) and common cheap chemical membrane cleaning methods. The results showed that air backpulse alone had a minor $(9 \%)$ effect on the membrane cleaning. The alternation of $\mathrm{NaOH}(1 \%)$ solution with the NaClO (200 mg/L of Free chlorine) was the most effective approach for membrane cleaning. The cleaning effectiveness was $95.1 \%$ for $50 \mathrm{~nm}$ membrane and $89 \%$ for $200 \mathrm{~nm}$ membrane, indicating that membranes used for hydrolyzed lignocellulosic biomass filtration can be effectively cleaned using affordable and accessible chemicals.
\end{abstract}

Keywords - ceramic membranes, cleaning, fouling, lignocellulosic biomass

\section{INTRODUCTION}

Lignocellulosic biomass is abundant on Earth with an annual global production of about 181.5 billion tonnes. Around 7 billion tonnes are used as fodder or for energetic and material purposes and about 3.5 billion tonnes are produced as agricultural residues without any further use [1]. At the same time, lignocellulosic raw materials and bio-based primary products can be converted into high- value chemicals, e.g., biofuels, furfural, carbohydrates [2]. Traditionally, the conversion is one-way subsequent pretreatment, hydrolysis, fermentation, and product extraction. To facilitate product concentration, purification, and resource recovery, the introduction of membranes in the process stream has been recognized and tested in the treatment of lignocellulosic biomass after enzymatic hydrolysis [3]. Despite the high potential of membrane technologies, their efficiency is highly dependent on the properties of the liquid to be treated and membrane material.

Ceramic ultrafiltration membranes in comparison to polymeric membranes possess several advantages, including toleration to high temperatures and harsh chemical conditions, and a lifespan of 10-20 years [4], [5]. Therefore, ceramic membranes are widely used in food production, pharmaceutical, bioenergy, and other industries. At the same time, membrane operation is cumbersome, especially when fouling is tackled, since it reduces membrane performance efficiency by flux decline (in constant transmembrane pressure (TMP) systems) or increases TMP in constant flux systems. To maintain the membrane performance at a satisfactory level, regular membrane cleaning should be performed [6]. Cleaning procedures are commonly divided into physical (nonreagent) and chemical. While every physical cleaning method has different parameters affecting efficiency, chemical cleaning depends on four basic parameters: flow, reagent concentration, temperature, and contact time [7]. In 
the food industry, where organic compounds are the main foulants, it is considered that the cleaning should be performed at the same temperature as the filtration [7], to avoid protein crosslinking and denaturation [8]. The selection of the most appropriate cleaning agent and its concentration is crucial to avoid unwanted chemical reactions, damage of the membrane, or worsen contamination. Similarly, as in the food industry, the same issues have also been observed in the treatment of hydrolyzed biomass, where the solution contains lignocellulosic residue, released carbohydrates, and proteins, if enzymatic hydrolysis is performed [3]. All of these tend to foul the membranes.

To remove the organic foulants, alkaline reagents are the most widespread, since alkalis dissolve organic compounds, saponificate fats, and oils, and hydrolyze proteins [9], [10]. Nevertheless, the longevity of the cleaning procedure should be carefully evaluated to perform effective cleaning from one side, and not to terminate the production process for too long on the other. Although, general guidelines can be found on the cleaning of membranes fouled with different types of contaminants, every case must be evaluated individually. There are detailed recommendations available for various fields of the food industry [7], however, cleaning protocols for membranes applied in the treatment of hydrolyzed lignocellulosic biomass have not been reported or the data is limited. Within this study, the selection of the most appropriate treatment protocol for cleaning of ceramic ultrafiltration membranes after the filtration of hay hydrolysate was performed. To mimic industrial production, a laboratory pilot scale membrane system was used for the studies. Permeate flux was selected as the representative parameter to characterize membrane fouling. The general acceptance, that the lower the flux, the bigger the fouling was used to estimate the efficiency of the cleaning procedure.

\section{MATERIALS AND METHODS}

\section{A. Experimental Setup}

Filtration experiments and cleaning procedures were performed in a pilot-scale system (JWCMF - C.2, Jiangsu Jiuwu Hitech Co, China) equipped with a 30L AISI 316 tank with a water jacket for temperature control. The filtration setup (Fig. 1) was designed for constant flux filtration experiments with an air backpulse option. The constant feed flow was supplied by pump 4 (Grudfoss, CM5-4 A-R-GE-AQQE F-A-A-N) and regulation valves 5 and 12. Air backpulse was driven by the air compressor 21 , solenoid valves $15 ; 19 ; 20$, and a programmable logic controller for permeate flow, air intake, and air exhaust time control. Two mechanical pressure meters $(8,11)$ were used for the pressure measurement in feed flow and retentate flow. Flow meters were used to measure the flow of permeate (16) and retentate (13). The temperature was recorded using an electronic thermometer (6).

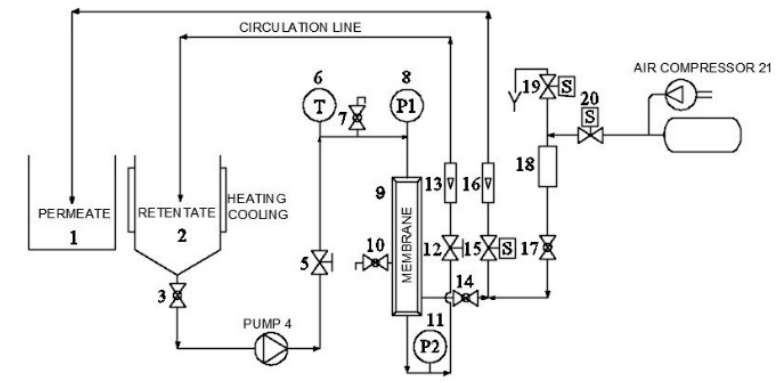

Fig. 1. Experimental filtration system with $30 \mathrm{~L}$ tank and $0.24 \mathrm{~m} 2$ membrane filtration area.

\section{B. Membranes}

Two tubular ceramic membranes from Jiangsu Jiuwu Hitech Co (Jiangsu, China) with a pore size of 50 and 200 $\mathrm{nm}$ were used for filtration. Both membranes were made of $\mathrm{TiO}_{2}$ filtering layer on $\alpha$-alumina support with 19 parallel feed flow channels, an outer diameter of $25.4 \mathrm{~mm}$, and a total length of $1016 \mathrm{~mm}$. The inner diameter of the feed flow channels was $3.3 \mathrm{~mm}$, the membrane area $0.24 \mathrm{~m}^{2}$, and the porosity $35 \%$. The hydraulic resistance for 50 and 200 $\mathrm{nm}$ membranes was calculated from the deionized water flux to $4.8 * 10^{-3}$ and $3.9 * 10^{-3}$ bar $^{2} \mathrm{hl}^{-1}$, respectively. The cross-flow velocity during filtration was $0.87 \mathrm{~ms}^{-1}$.

\section{Hydrolysate Preparation and Filtration}

Dried hay from semi-natural grasslands was used as a source material for hydrolysate production. The biomass was milled (Retsch SM100, Haan, Germany) to obtain particle size $\sim 1 \mathrm{~mm}$. Then, the biomass $(3 \% \mathrm{w} / \mathrm{v}$ in nanofiltered water) was thermally pre-treated/hydrolyzed $\left(121^{\circ} \mathrm{C}, 1\right.$ bar for 5 minutes) in a $30 \mathrm{l}$ AISI 316 reactor equipped with a mixer. Further, the hay solution was cooled to $30{ }^{\circ} \mathrm{C}$ and passed through the microfilter with a pore size of $1 \mu \mathrm{m}$ (Geyser, Russia) to remove major suspended solids able to block the ceramic membrane and the peristaltic pump. All tests were performed using $15 \mathrm{l}$ of hydrolysed hay solution at $30^{\circ} \mathrm{C}$ that is the reported optimum concentration for biomass hydrolysis in the given reactor system [11].

Transmembrane pressure (TMP) was calculated according to (1) :

$$
T M P=\frac{P_{1}+P_{2}}{2}
$$
$\mathrm{MPa}$;

where: $-\mathrm{P}_{1}$ feed pressure, $\mathrm{MPa} ; \mathrm{P}_{2}$ - retentate pressure,

After each filtration test, the membranes were cleaned using selected chemicals.

\section{Biomass granulometric composition}

To analyze biomass particle size and evaluate the efficiency of microfiltration, the granulometric composition of the biomass collected from the microfilter was determined with the vibration separator Controls D 407 (Newzeland) and different sieve sizes $(<63,63,125$, 250, 500, 1000). 
Environment. Technology. Resources. Rezekne, Latvia Proceedings of the $13^{\text {th }}$ International Scientific and Practical Conference. Volume 3, 89-94

\section{E. Physical Membrane Cleaning}

During air-water backpulse cleaning, the air was supplied by the compressor through valve 7 (Fig. 1). The air compressor pressure was set to 3 bar. The backpulsing was performed for 5 sec. every 5 mins. The air exhaust time was 8 mins.

\section{F. Chemical Membrane Cleaning}

The cleaning of membranes was performed according to the scheme in Table 1 at TMP of 0.5 bar and included 8 different test setups at a constant temperature regime. Before each chemical cleaning procedure, an initial rinse of the fouled membrane and the filtration system with deionized water at room temperature and a TMP of 0.5 bar was performed for $3 \mathrm{~min}$. After the rinse, permeate flux $\left(\mathrm{Q}_{\mathrm{b}}\right)$ with deionized water at $25^{\circ} \mathrm{C}$ and average TMP of 2.5 bar was measured. The second rinse (0.5 bar TMP) was performed with deionized water to remove chemical cleaning agents after the cleaning. Finally, permeate flux $\left(\mathrm{Q}_{\mathrm{a}}\right)$ was measured with deionized water at temperature $25^{\circ} \mathrm{C}$ and TMP average 2.5 bar.

\section{G. Cleaning Efficiency Calculations}

Before every filtration experiment, the initial water flux of the clean membrane was measured using deionized water. The cleaning efficiency was evaluated as permeate flux recovery. The final flux recovery was based on the measurements of deionized water permeate flux through the cleaned membrane. Cleaning efficiency (\%) was calculated according to (2)

$$
F=\frac{Q_{b}-Q_{a}}{Q_{b}} \times 100
$$

where: $Q_{a}$ - deionized water permeate flux after cleaning, $\mathrm{l} / \mathrm{h} ; \mathrm{Q}_{\mathrm{b}}$ - deionized water permeate flux before cleaning, $\mathrm{l} / \mathrm{h}$.

TABLE 1 TESTED CLEANING APPROACHES FOR 50 AND 200 NM CERAMIC MEMBRANES

\begin{tabular}{|c|c|c|c|c|c|}
\hline$\stackrel{\square}{\mathscr{E}}$ & $\begin{array}{c}\text { Membr } \\
\text { ane } \\
\text { pore } \\
\text { size, } \mathbf{n m}\end{array}$ & $\begin{array}{c}\text { Cleaning } \\
\text { agents }\end{array}$ & $\begin{array}{c}\text { Agent } \\
\text { concent } \\
\text { ration, } \\
\% \\
\end{array}$ & $\begin{array}{l}\text { Cleaning } \\
\text { time, min }\end{array}$ & $\begin{array}{c}\text { Tempe } \\
\text { rature, } \\
{ }^{\circ} \mathrm{C}\end{array}$ \\
\hline 1 & 50 & $\mathrm{HNO}_{3}$ & 1 & 30 & 50 \\
\hline 2 & 50 & $\mathrm{NaOH}$ & 1 & 30 & 60 \\
\hline 3 & 50 & backpulse & - & 30 & 30 \\
\hline 4 & 50 & $\mathrm{NaOCl}$ & 0.023 & 30 & 30 \\
\hline 5 & 50 & $\begin{array}{l}\text { backpulse } \\
\text { and } \mathrm{NaOH}\end{array}$ & 1 & $30+30$ & $\begin{array}{l}30 \text { and } \\
50\end{array}$ \\
\hline 6 & 50 & $\begin{array}{l}\mathrm{NaOH} \text { and } \\
\mathrm{NaOCl}\end{array}$ & $\begin{array}{l}1 \text { and } \\
0.02\end{array}$ & $30+30$ & $\begin{array}{l}50 \text { and } \\
30\end{array}$ \\
\hline 7 & 200 & $\begin{array}{l}\mathrm{NaOH} \text { and } \\
\mathrm{NaOCl}\end{array}$ & $\begin{array}{l}1 \text { and } \\
0.02\end{array}$ & $30+30$ & $\begin{array}{l}50 \text { and } \\
30\end{array}$ \\
\hline 8 & 200 & $\begin{array}{l}\mathrm{NaOCl} \text { and } \\
\mathrm{NaOH}\end{array}$ & $\begin{array}{l}0.02 \text { and } \\
1\end{array}$ & $30+30$ & $\begin{array}{l}30 \text { and } \\
50\end{array}$ \\
\hline
\end{tabular}

\section{RESULTS AND DISCUSSION}

The initial permeability of the two membranes $(50 \mathrm{~nm}$ and $200 \mathrm{~nm}$ ) was determined before the experiments by linear regression of the deionized water flux $(\mathrm{J})$ against the TMP (Fig.2).

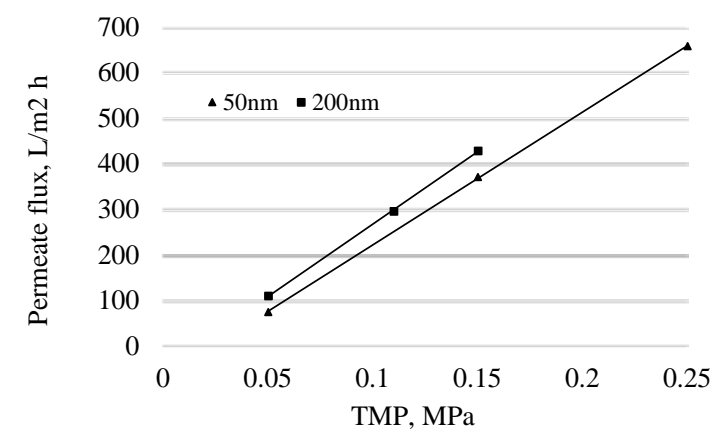

Fig. 2. Water flux against transmembrane pressure for the $50 \mathrm{~nm}(\boldsymbol{\Delta})$ and $200 \mathrm{~nm}(\boldsymbol{\square})$ membranes at $25^{\circ} \mathrm{C}$.

As expected, the permeate flux ( $\mathrm{J}$ ) of deionized water for clean membranes was higher for $200 \mathrm{~nm}$ membrane if compared to $50 \mathrm{~nm}$ membrane. The estimated maximal permeate flux in the pilot system was $1250 \mathrm{~m}^{2} \mathrm{hl}^{-1}$ for 50 nm membrane and $1653 \mathrm{~m}^{2} \mathrm{hl}^{-1}$ for $200 \mathrm{~nm}$ membrane.

\section{A. Biomass and hydrolyzate characterization}

The estimated granulometric composition revealed that the particles are distributed within the whole range of used sieves. The highest fraction attributed to 125 and $250 \mu \mathrm{m}$ sizes (Table 2). The fractions were acceptable for further filtration tests.

The estimated physical parameters of the hay hydrolysate (186 NTU turbidity, pH 5.1 - 5.5, conductivity $1850 \mu \mathrm{S} / \mathrm{cm}$ and zeta-potential of $17.5 \pm 4.5 \mathrm{mV}$ ) were representative of both thermally treated/hydrolyzed biomass and organic filtrates [12].

TABLE 2 GRANULOMETRIC COMPOSITION OF LIGNOCELLULOSIC BIOMASS

\begin{tabular}{|c|c|}
\hline Sieve eye size, $\boldsymbol{\mu m}$ & Amount, $\%$ \\
\hline 1000 & 21,8 \\
\hline 500 & 10,6 \\
\hline 250 & 24,7 \\
\hline 125 & 25,7 \\
\hline 63 & 10,7 \\
\hline$<63$ & 6,5 \\
\hline
\end{tabular}

\section{B. Permeate Flux}

Two different stages concerning the permeate flux were distinguished in the thermally hydrolysed hay filtration process. In the first stage, permeate flux decreased significantly (from $28 \mathrm{hl}^{-1}$ to $10 \mathrm{hl}^{-1}$ ). This stage lasted approximately 15 minutes for both selected membranes. Then the permeate flux reached a steady-state and remained constant (Fig. 3). The calculated trendlines of the permeate flux decrease were similar when compared with 
other studies utilizing 50 and 200 nm ceramic membranes [13], [14].

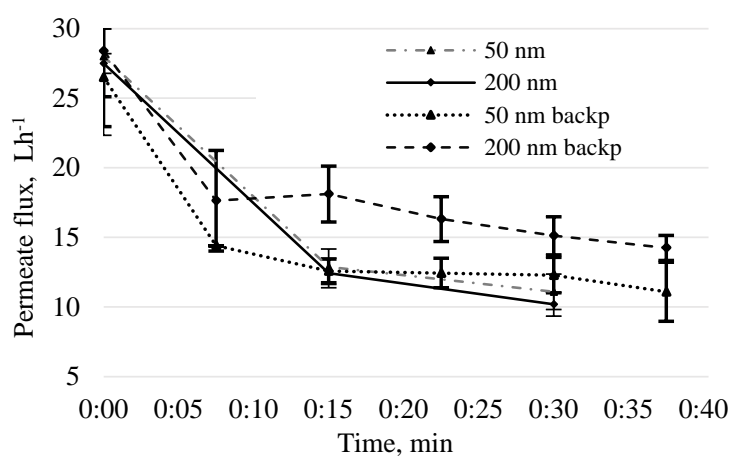

Fig. 3. The permeate flux of thermally hydrolyzed hay solution at $30^{\circ} \mathrm{C}$ with and without air backpulse for $50 \mathrm{~nm}$ and $200 \mathrm{~nm}$ ceramic membranes $(\mathrm{t}=2.02, \mathrm{P}=0.05)$.

To enhance permeation flux, permeate or water can be used for membrane backwashing [15]. Alternatively, air backpulsing can be used [16]. In this study, backpulsing was used to enhance permeation during the hay hydrolysate filtration. The results showed a positive effect of air backpulsing only for a $200 \mathrm{~nm}$ membrane. And no effect for the $50 \mathrm{~nm}$ membrane. The $200 \mathrm{~nm}$ membrane air backpulsing could withstand permeate flux near $15 \mathrm{hl}^{-1}$ for 37 mins (until the full volume of thermally hydrolyzed hay was filtered) (Figure 3).

Similar results for the positive effect of air backpulsing for larger pore size membranes were obtained by [17] for synthetic leather industry wastewater and [18] for raw sugar cane juice filtration. The authors of both studies indicated no positive effect for 20 and $50 \mathrm{~nm}$ membranes. Thus, the results of the current study with lignocellulosic hydrolysate complement other findings where air backpulsing is useful for ceramic membranes of microfiltration range/or some loose ultrafiltration range (100-200 nm).

Furthermore, air backpulsing shortened the first phase of intensive flux decline from 15 minutes to 7 minutes. This phenomenon could be attributed to a small-size particle layer disruption and resuspension, leading to more intensive flux decline and faster stable phase onset.

\section{Cleaning of Membranes}

All of the thermally hydrolysed hay filtration experiments were followed by cleaning methods (Table 1). First, the efficiency of single-step cleaning methods (Test 1-4, Table 1) for a $50 \mathrm{~nm}$ membrane was evaluated (Fig. 4). Assessment of $\mathrm{HNO}_{3}(1 \%)$ acid solution resulted in no positive effect on the membrane cleaning. This phenomenon may be attributed to the fact that the filtered solution of hydrolysed hay is of organic origin, whereas acids are effective for dissolving inorganic contaminants like metal oxides [8],[19]. The results were therefore excluded from the graphs. $\mathrm{NaOH}(1 \%)$ solution resulted in a $46.2 \%$ increase of permeate flux in 30 mins showing the best results obtained by single-step cleaning technique
(Fig.

4).

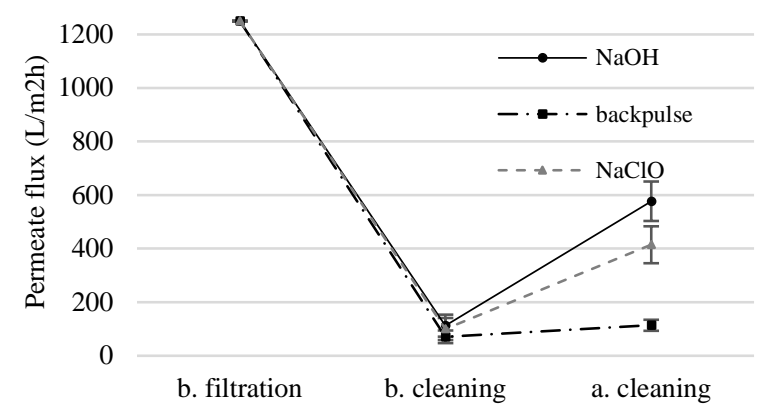

Fig. 4. The permeate flux for $50 \mathrm{~nm}$ membrane before filtration ("b. filtration"), after the filtration of thermally hydrolyzed hay solution ("b. cleaning”), and after the cleaning (“a. cleaning”).

The Zeta potential of the filtering solution was $17.5 \pm 4.5$ $\mathrm{mV}$, meaning that the solution was in the unstable region, and particle aggregation and sedimentation could take place on the membrane surface [20]. In this case, it can be beneficial to raise the $\mathrm{pH}$ by adding alkali, promoting particle desorption from the membrane surface. The common concentrations of alkalis in these systems are in the range of $0.5-2 \% \mathrm{w} / \mathrm{v}$ [8].

Water + air backpulse showed minimal (9\%) effect on the cleaning of $50 \mathrm{~nm}$ membrane, probably because residual hay particles present in the hydrolysate were much bigger in size than membrane pores. Furthermore, the size of air bubbles generated by the compressor was two orders of magnitude larger than the size of membrane pores, thus, air bubbles could not enter and clean the pores. Thus, airbased hydraulic cleaning techniques are unsuitable for microfiltration membranes [21], [22].

Application of $\mathrm{NaOCl}$ solution containing $200 \mathrm{mg} / \mathrm{L}$ of free chlorine (shock chlorination technique) resulted in $33.2 \%$ cleaning efficiency.

Since single-step cleaning approaches showed only modest results, two-step cleaning approaches were tested (Tests 5-6 in Table 1) to evaluate the potential use of apparently different chemicals in a single set-up.

The combination of air backpulse and $\mathrm{NaOH}$ resulted in $21 \%$ cleaning efficiency (Fig. 5),

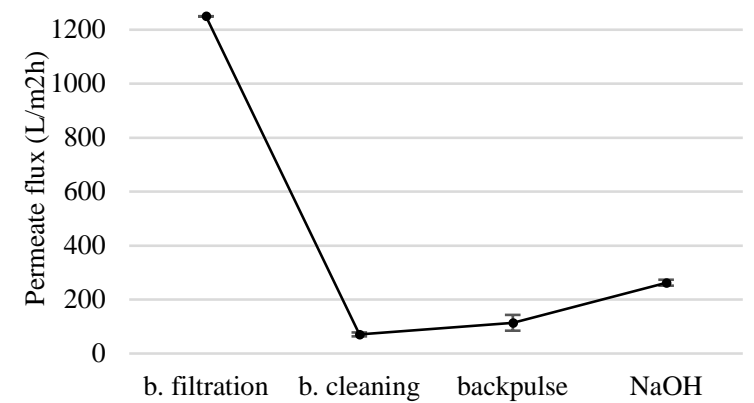

Fig. 5. The permeate flux for $50 \mathrm{~nm}$ membrane before filtration, after the filtration of thermally hydrolyzed hay solution, and after the cleaning with air-water backpulse and $1 \% \mathrm{NaOH}$ solution. b.-before, a.-after.

which is low considering that in single-step cleaning approach with $\mathrm{NaOH}$ efficiency was $46.2 \%$. Probably 
Environment. Technology. Resources. Rezekne, Latvia Proceedings of the $13^{\text {th }}$ International Scientific and Practical Conference. Volume 3, 89-94

backpulse disturbed debris layer presented in the pilot system walls, resulting in secondary contamination and decreased $\mathrm{NaOH}$ efficiency.

Subsequent use of $\mathrm{NaOH}$ and $\mathrm{NaClO}$ showed the best performance resulting in $95.1 \%$ cleaning efficiency (Fig. $6)$.

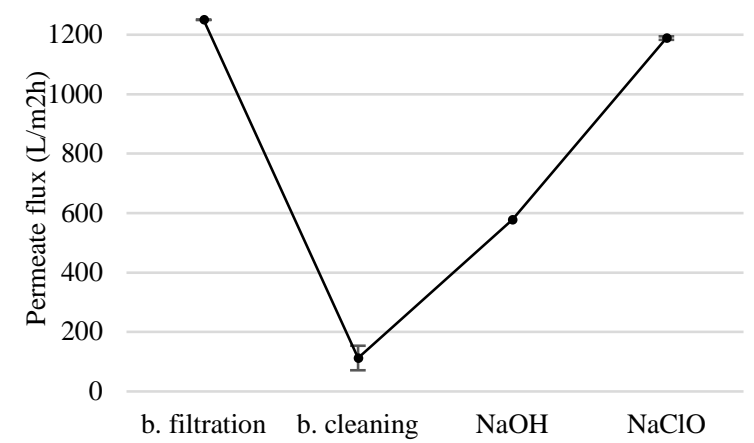

Fig. 6. The permeate flux for $50 \mathrm{~nm}$ membrane before filtration, after the filtration of thermally hydrolyzed hay solution, and after the sequencing cleaning with $1 \% \mathrm{NaOH}$ solution and $0.023 \% \mathrm{NaClO}$ solution. b.-before, a.-after.

Such consecutive use of alkali and active chlorine has been also shown to be effective for removing biofilms from pipe walls and killing Bacillus spores in a bulk [23]. After successful selection of the treatment approach, filtration of hydrolysed hay was validated for the $200 \mathrm{~nm}$ membrane. The results demonstrated $89 \%$ efficiency for the consecutive use of $\mathrm{NaOH}$ and $\mathrm{NaClO}$ (Fig. 7), meaning that the method is equally effective for different size ultrafiltration membranes.

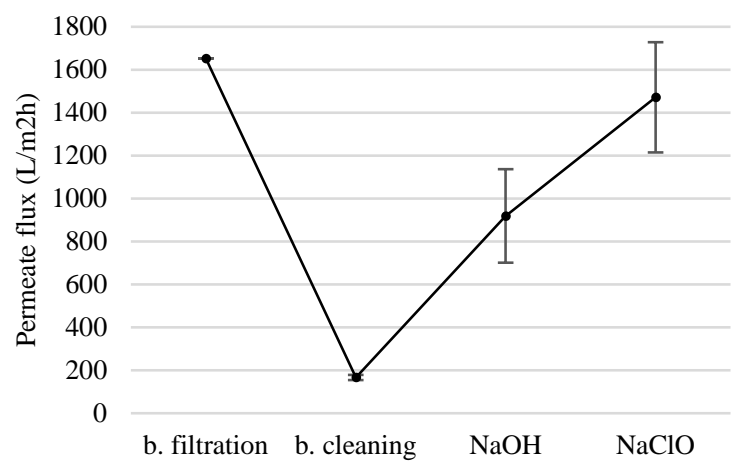

Fig. 7. The permeate flux for $200 \mathrm{~nm}$ membrane before filtration, after the filtration of thermally hydrolyzed hay solution, and after the sequencing cleaning with $1 \% \mathrm{NaOH}$ solution $0.023 \% \mathrm{NaClO}$ solution. b.-before, a.-after.

To demonstrate the efficiency of the selected step-wise treatment, $\mathrm{NaOH}$ and $\mathrm{NaClO}$ application was inversed. As expected, the two-step protocol resulted in a mere $46 \%$ cleaning efficiency (Fig. 8), which was lower than using the opposite sequence of reagents.

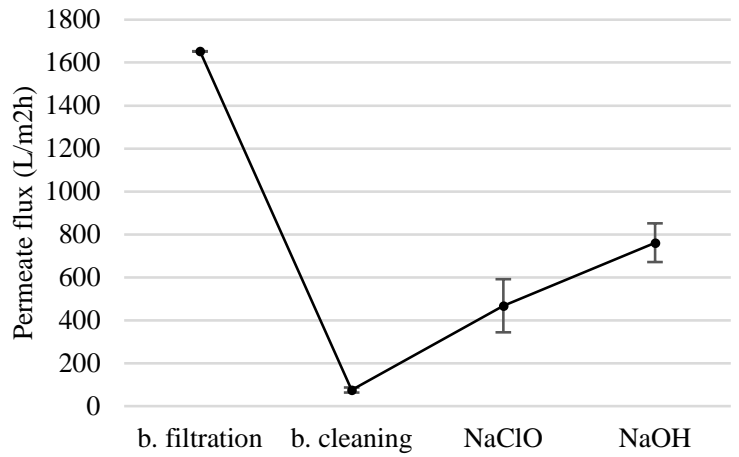

Fig. 8. The permeate flux for $200 \mathrm{~nm}$ membrane before filtration, after the filtration of thermally hydrolyzed hay solution, and after the sequencing cleaning with $0.023 \% \mathrm{NaClO}$ solution and $1 \% \mathrm{NaOH}$ solution. b.-before, a.-after.

This phenomenon may be attributed to the fact that $\mathrm{NaOH}$ loosens deposits on the membrane surface and disperse them, while $\mathrm{NaClO}$ promotes a gel layer on the membrane surface to decompose by oxidation and then fall off. The cleaning process is not as effective if active chlorine cannot penetrate the gel layer and effective reaction occurs only with loose particles. Thus, the sequence of the reagents is of big importance.

\section{CONCLUSIONS}

Multiple physical and chemical methods have been tested to clean ceramic membranes after the filtration of hydrolyzed lignocellulosic biomass to extract fermentable carbohydrates. The results showed that single-step treatment does not provide efficient cleaning and result in less than $50 \%$ cleaning efficiency. Alternation of $\mathrm{NaOH}(1$ $\%)$ solution with the $\mathrm{NaClO}(0.023 \%)$ was the most effective approach for membrane cleaning resulting in 95.1 $\%$ for $50 \mathrm{~nm}$ membrane and $89 \%$ cleaning efficiency for $200 \mathrm{~nm}$ membrane. Thus, membranes used industrial production of fermentable carbohydrates from hydrolyzed lignocellulosic biomass can be effectively and quickly cleaned with conventional inexpensive chemicals.

\section{ACKNOWLEDGMENT}

The work has been funded by ERDF Project "Zero-tolow-waste technology for simultaneous production of liquid biofuel and biogas from biomass", No. 1.1.1.1/18/A075.

\section{REFERENCES}

[1] N. Dahmen, I. Lewandowski, S. Zibek, and A. Weidtmann, "Integrated lignocellulosic value chains in a growing bioeconomy: Status quo and perspectives,” GCB Bioenergy, vol. 11, no. 1, pp. 107-117, 2019.

[2] O. Rosales-Calderon and V. Arantes, A review on commercialscale high-value products that can be produced alongside cellulosic ethanol, vol. 12, no. 1. BioMed Central, 2019.

[3] A. R. P. P. Weerasuriya Arachchige, L. Mezule, and T. Juhna, "Separation of reducing sugars from lignocellulosic hydrolysate: Membrane experiments \& system dynamic modelling,” Agron. Res., vol. 18, no. Special Issue 1, pp. 1099-1106, 2020.

[4] R. J. Ciora and P. K. T. Liu, "Ceramic membranes for environmental related applications,” Fluid - Part. Sep. J., vol. 15, 
no. 1, pp. 51-60, 2003.

[5] S. Luque, D. Gomez, and J. R. Alvarez, "Industrial Applications of Porous Ceramic Membranes (Pressure-Driven Processes)," in Membrane Science and Technology, vol. 13, Elsevier, 2008, pp. 177-216.

[6] W. Li et al., "Ceramic membrane fouling and cleaning during ultrafiltration of limed sugarcane juice,” Sep. Purif. Technol., vol. 190, no. July 2017, pp. 9-24, 2018.

[7] Tetra Pak Processing Systems, Cleaning in place - a guide to cleaning technology in the food processing industry, no. Technology, Engineering, Agriculture. Tetra Pack Processing Systems, 2015.

[8] H. Li and V. Chen, "Membrane Fouling and Cleaning in Food and Bioprocessing,” in Membrane Technology, First Edit., no. July, Elsevier Ltd, 2010, pp. 213-254.

[9] D. C. Olk et al., "Environmental and Agricultural Relevance of Humic Fractions Extracted by Alkali from Soils and Natural Waters,” J. Environ. Qual., vol. 48, no. 2, pp. 217-232, 2019.

[10] H. Li, “Cleaning Cycle of Fouled Membranes," in Encyclopedia of Membranes, E. Drioli and L. Giorno, Eds. Berlin, Heidelberg: Springer Berlin Heidelberg, 2016, pp. 412-416.

[11] L. Mezule and A. Civzele, "Bioprospecting white-rot basidiomycete irpex lacteus for improved extraction of lignocellulose-degrading enzymes and their further application,” J. Fungi, vol. 6, no. 4, pp. 1-10, 2020.

[12] L. De Angelis and M. M. F. De Cortalezzi, "Ceramic membrane filtration of organic compounds: Effect of concentration, $\mathrm{pH}$, and mixtures interactions on fouling," Sep. Purif. Technol., vol. 118, pp. 762-775, 2013.

[13] S. Popović, S. Milanović, M. Iličić, M. Djurić, and M. Tekić, "Flux recovery of tubular ceramic membranes fouled with whey proteins,” Desalination, vol. 249, no. 1, pp. 293-300, 2009.

[14] R. Pérez-Gálvez, E. M. Guadix, J. Berg, and A. Guadix,
"Operation and cleaning of ceramic membranes for the filtration of fish press liquor,” J. Memb. Sci., vol. 384, no. November, pp. 142-148, 2011.

[15] R. Shang et al., "Hydraulically irreversible fouling on ceramic MF/UF membranes: Comparison of fouling indices, foulant composition and irreversible pore narrowing," Sep. Purif. Technol., vol. 147, pp. 303-310, 2015.

[16] S. Mozia, K. Szymański, B. Michalkiewicz, B. Tryba, M. Toyoda, and A. W. Morawski, "Effect of process parameters on fouling and stability of $\mathrm{MF} / \mathrm{UF} \mathrm{TiO} 2$ membranes in a photocatalytic membrane reactor,” Sep. Purif. Technol., vol. 142, pp. 137-148, 2015.

[17] Q. Zhang et al., "Performance study of $\mathrm{ZrO} 2$ ceramic microfiltration membranes used in pretreatment of DMF wastewater," Desalination, vol. 346, pp. 1-8, 2014.

[18] V. Jegatheesan, D. D. Phong, L. Shu, and R. Ben Aim, "Performance of ceramic micro- and ultrafiltration membranes treating limed and partially clarified sugar cane juice,” J. Memb. Sci., vol. 327, no. 1-2, pp. 69-77, 2009.

[19] C. V. Vedavyasan, Encyclopedia of Membranes, no. i. Springer, Berlin, Heidelberg, 2016.

[20] “Zeta potential: An Introduction in 30 minutes,” 2011.

[21] X. Shi, G. Tal, N. P. Hankins, and V. Gitis, "Fouling and cleaning of ultrafiltration membranes: A review,” J. Water Process Eng., vol. 1, pp. 121-138, 2014.

[22] D. Kuzmenko, E. Arkhangelsky, S. Belfer, V. Freger, and V. Gitis, "Chemical cleaning of UF membranes fouled by BSA," Desalination, vol. 179, no. 1-3 SPEC. ISS., pp. 323-333, 2005.

[23] K. Gruskevica, "Decontamination of water supply systems after deliberate pollution,” 2015 